\title{
F-wave and Cervical Somatosensory Response Conduction from the Seventh Cervical Spinous Process to Cortex in Multiple Sclerosis
}

\author{
ANDREW EISEN AND KENNETH NUDLEMAN
}

SUMMARY: Transit (conduction) times from the wrist to the seventh cervical spinous process $\left(C_{7}\right)$ were measured by using the $F$-wave response (TA) and the cervical somatosensory response (SEPC). The mean values obtained in 25 controls were $10.1 \pm 0.9 \mathrm{~s}^{-3}$ and $10.9 \pm 1.0 \mathrm{~s}^{-3}$ respectively. The $0.8 \pm 1.0 \mathrm{~s}^{-3}$ difference between the two methods represents central delay of $S E P C$, possibly at the level of the dorsal root ganglion. The mean onset latency of the cortical somatosensory response ( $\left.S E P_{A}\right)$ evoked by median nerve stimulation in the same subjects was $15.5 \pm 1.0$ $s_{-}{ }^{3}$. Transit time from $C_{7}$ to the cortex (TB)

RESUMÉ: Le temps de transit du poignet au processus spinal de $C_{7} f u$ mesuré en utilisant la réponse à l'onde $F(T A)$ et la réponse somatosensitive cervicale (SEPC). Les valeurs moyennes obtenues chez $25 \mathrm{su}$ jets contrôles furent respectivement de 10.1 $\pm 0.9 \mathrm{~s}^{3}$ et $10.9 \pm 1.0 \mathrm{~s}^{3}$. La différence de $0.8 \pm 1.0 \mathrm{~s}^{3}(p<0.01)$ entre les deux méthodes représente le délai central du SEPC au niveau du ganglion spinal. La latence de départ moyenne de la réponse somatosensitive corticale (SEPA) produite par stimulation du nerf médian chez les mêmes sujets fut de $15.5 \pm 1.0 \mathrm{~s}^{-}{ }^{3}$. Le temps de transit de $C_{7}$ au cortex (TB) peut given by either $S E P_{A}-T_{A}$ or $S E P_{A}$ $S E P C-0.8$, where 0.8 is the necessary corrective factor for central delay of $S E P C$, was $5.3 \pm 1.0 \mathrm{~s}^{-3}$. These techniques were applied to 10 patients suspected of having multiple sclerosis, but without clinical evidence of involvement above $C_{7}$. Six of the 10 cases showed prolongation of $T B$. In 4 of these, this could only be calculated by the $F$-wave method since SEPC was absent. It is concluded that transit times derived from either the F-wave or SEPC are equally valid and interchangeable. The absence of one response allows for its replacement by the other.

être calculé par les formules $S E P_{A}-T_{A}$ ou $S E P_{A}-S E P C-0.8$, ou 0.8 représente le facteur de correction nécessaire pour le délai central du $S E P C$. Ce chiffre est de $5.3 \pm 1.0 \mathrm{~s}^{-3}$ avec les deux formules. Nous avons utilisé ces techniques chez 6 patients possiblement atteints de sclérose en plaques, mais sans évidence clinique d'atteinte supérieure à $C_{7}$. Cinq des 6 cas eurent une prolongation du TB et chez 4 de ceux-çi, ceci ne pouvait être calculé que par la méthode de l'onde $F$, car le SEPC était absente. Nous concluons que les deux méthodes (Onde F ou SEPC) sont également valables et interchangeables si nécessaire.
From the Department of Neurology and Neurosurgery, McGill University, Montreal, Canada.

Reprint requests to Dr. Andrew Eisen, Montreal Neurological Hospital, 3801 University Street, Montreal, Quebec, H3A 2B4, Canada.

This work was supported by grants from the Multiple Sclerosis Society of Canada and the Muscular Dystrophy Association of Canada.

\section{INTRODUCTION}

In a previous study from this laboratory (Eisen and Nudleman, In Press), a technique was used to measure indirectly spinal cord conduction employing F-wave and somatosensory responses. It was shown that spinal cord transit time and conduction velocity were slowed in a significant number of patients with confirmed multiple sclerosis. The method, in essence, depends upon the difference between the transit time from the wrist to the cortex recorded from the cortically evoked somatosensory response, and the transit time from the wrist to the spinal cord using the F-wave technique (Kimura, 1974). The same principles are then applied to the leg. By subtracting the cervical cord to cortex transit time from the lumbar cord to cortex transit time, it is possible to arrive at a transit time from $L_{1}$ to $C_{7}$ (Dorfman, 1977).

The technique, although useful, had a number of limitations. In particular, it was assumed that the velocity through the peripheral nervous system measured through the F-wave (motor fibers) could be equated with velocity through the central nervous system recorded via somatosensory evoked responses (sensory fibers). In addition, seven independent measurements are required to calculate cord conduction velocity. Accurate onset latency of the somatosensory responses is crucial to the final calculation. Although this was not a serious problem when measuring the response evoked by stimulating the median nerve at the wrist, the response recorded from stimulating the peroneal nerve (or posterior tibial nerve) at the knee is such that its onset is not as easily definable (Tsumoto et al., 1972). 
The present study was undertaken to answer the following questions: 1 . Is it valid to equate conduction time and velocity from the wrist to the $C_{7}$ spinous process using the $\mathrm{F}$-wave method with values over exactly the same segment of nerve obtained by recording the cervical somatosensory response? 2. Is there a difference in the transmission time between $\mathrm{C}_{7}$ and the contralateral cortex, which can be derived by subtracting either of the above from the onset latency of the cortically evoked somatosensory response? 3. Would this measurement be of value in indicating disease above the level of $C_{7}$ spinal segment in patients suspected of having multiple sclerosis, but in whom the clinical deficit is limited to the legs or below the level of $\mathrm{C}_{7}$ ?

\section{METHODS}

Electrophysiological studies were conducted on 25 healthy volunteers of both sexes aged between 15 and 71 years (mean 37.85 years). The experiments were performed with the subject lying comfortably supine, in a semidarkened air conditioned room, in which the ambient temperature was maintained at between 20 and $22^{\circ} \mathrm{C}$. Subjects were encouraged to relax without becoming drowsy or sleepy.

\section{Stimulation:}

The median nerve was stimulated at the wrist using surface electrodes. For $\mathrm{M}$ and $\mathrm{F}$-wave recordings, the stimulus intensity was supramaximal, usually being about 10 to $15 \mathrm{~mA}$. Stimuli were delivered at a rate of $1 \mathrm{~Hz}$, with a duration of $0.2 \mathrm{~s}^{3}$. When recording the somatosensory responses and mixed nerve action potential, the stimulus intensity was reduced enough to be without discomfort, but still sufficient to produce a clearly visible twitch of the thenar muscle group.

\section{Recording:}

$M$ and $F$-wave responses were recorded from the thenar muscle using gold disc surface electrodes. The active electrode was placed over the muscle belly and the indifferent electrode over its tendon. The latency of the F-wave response was taken from the wave form having the shortest latency out of 4 to 8 trials. In the majority of cases, no difficulty was encountered in eliciting F-waves. However, when necessary, responses could be augmented by slight voluntary contraction of the muscle under study, and/or by making a fist with the contralateral hand (Eisen et al., $1977 \mathrm{a}$ and b).

The latency of the mixed nerve action potential recorded from Erb's point was measured as the initial negative deflection of this reponse, which was recorded using surface disc electrodes. The active electrode was placed just behind the posterior border of the sternocleidomastoid muscle and $2 \mathrm{~cm}$. above the clavicle. The indifferent electrode was positioned on the sterno-manubrial joint.

Cervical somatosensory evoked responses were recorded by surface electrodes placed just rostral to the $C_{7}$ spinous process (active electrode) and on the mid-forehead (indifferent electrode).

The cortical somatosensory evoked response was recorded through a surface electrode positioned over $\mathrm{C}_{3}$ or $\mathrm{C}_{4}$ (international 10 - 20 system) contralateral to the side of stimulation. The differential electrode was placed on the forehead $2-3 \mathrm{~cm}$. above the one employed for recording the cervical somatosensory response.

The cortical somatosensory response was recorded utilizing differential amplifiers having a flat frequency of $0.2 \mathrm{~Hz}$ to $500 \mathrm{~Hz}$, this bandwidth being Calculations:

1. Using the $F$-wave response the transit time from the wrist to $C_{7}$ designated as TA is given by:

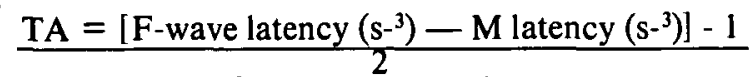

assuming a central delay of $1 \mathrm{~s}^{-3}$ (Renshaw, 1941).

F-wave impulse velocity $\left(\mathrm{ms}^{-1}\right)=$

Distance between stimulation site and $C_{7}$ spinous process $\left(\mathrm{m}^{-3}\right)$

$$
\text { TA }\left(\mathrm{s}^{-3}\right)
$$

2. Recording the cervical somatosensory evoked response, the transit time over the same segment of nerve (wrist to $C_{7}$ ) is designated as SEPC $\left(\mathrm{s}^{-}{ }^{3}\right)$, and the conduction velocity between these two points is given by:

$$
\text { Distance between stimulation site and } \mathrm{C}_{7} \text { spinous process }\left(\mathrm{m}^{-}{ }^{3}\right)
$$

$$
\text { SEPC }\left(\mathrm{s}^{-3}\right)
$$

The distance $\left(\mathrm{m}^{-3}\right)$ between the wrist and the $\mathrm{C}_{7}$ spinous process was measured with the subject sitting up and the arm outstretched horizontally.

3. Transit time to the contralateral cortex $\left(\mathrm{s}^{-}{ }^{3}\right)$ designated as TB is given by:

Onset latency $\left(\mathrm{s}^{-}\right)$of the cortical somatosensory evoked response designated as SEPA -

$\mathrm{TA}$, (when recording the F-wave response)

or

SEPC (when recording the cervical somatosensory response).

Ten patients aged between 23 and 47 years (mean 37.5 years), suspected of having multiple sclerosis but in whom the clinical deficit was limited to the lower limbs or below the $\mathrm{C}_{7}$ spinal segment, gave informed consent to undergo the same electrophysiological testing as the control group. They were examined clinically at the time of testing. 
TABLE 1

Transit times and conduction velocites derived from

$F$-wave and cervical somatosensory responses in 25 normal subjects

\begin{tabular}{lllll} 
& $\begin{array}{l}\text { Utilizing } \\
\text { F-wave } \\
\text { response }\end{array}$ & $\begin{array}{l}\text { Utilizing } \\
\text { Cervical } \\
\text { Somatosensory } \\
\text { response }\end{array}$ & Difference & p value (t value) \\
\hline Transit time & $10.1 \pm 0.93$ & $10.9 \pm 1.0$ & $0.77 \pm 1.0$ & $<0.01(\mathrm{t}=2.71)$ \\
wrist to $\mathrm{C}_{7}\left(\mathrm{~s}^{-3}\right)$ & $(8.6-12.1)$ & $(8.9-13.1)$ & & \\
Conduction velocity & $65.0 \pm 5.6$ & $60.4 \pm 3.5$ & $4.6 \pm 6.2$ & $<0.01(\mathrm{t}=3.34)$ \\
wrist to $\mathrm{C}_{7}\left(\mathrm{~m}^{-1}\right)$ & $(54.7-75.7)$ & $(53.6-68.5)$ & & \\
Transit time $\mathrm{C}_{7}$ & $5.3 \pm 1.0$ & $4.6 \pm 0.84$ & $0.74 \pm 1.1$ & $<0.02(\mathrm{t}=2.52)$ \\
to cortex $\left(\mathrm{s}^{-}{ }^{3}\right)$ & $(4.05-7.5)$ & $(3.6-6.2)$ & & \\
\hline
\end{tabular}

Values given as mean $\pm 1 \mathrm{SD}$, ranges within the brackets.

TABLE 2

Somatosensory Studies in Patients with "Spinal Form" of Multiple Sclerosis

\begin{tabular}{|c|c|c|c|c|}
\hline Case Age & $\begin{array}{l}\text { Velocity from } \\
\text { wrist to } C_{7} \\
(m-1)\end{array}$ & $\begin{array}{l}\text { SEPA } \\
\left(s \cdot{ }^{3}\right)\end{array}$ & $\begin{array}{l}\text { SEPC } \\
\left(s^{-3}\right)\end{array}$ & $\begin{array}{l}\mathrm{TB} \\
\left(\mathrm{s}^{-3}\right)\end{array}$ \\
\hline $\begin{array}{l}\text { 1. J.H. (F) } 40 \\
\text { 2. J.L. (F) } 42 \\
\text { 3. F.A. (F) } 46 \\
\text { 4. E.A. (F) } 47 \\
\text { 5. T.S. (M) } 29 \\
\text { 6. A.L. (F) } 23 \\
\text { 7. M.S. (M) } 39 \\
\text { 8. F.B. (F) } 32 \\
\text { 9. M.S. (F) } 42 \\
\text { 10. B.C. (F) } 36 \\
\end{array}$ & $\begin{array}{l}61.4 \\
54.7 \\
57.8 \\
58.1 \\
57.0 \\
70.8 \\
61.1 \\
65.6 \\
63.3 \\
59.4 \\
\end{array}$ & $\begin{array}{l}28.5 \\
24.6 \\
16.0^{*} \\
26.9^{*} \\
23.8^{*} \\
15.8^{*} \\
16.9^{*} \\
14.7^{*} \\
16.9^{*} \\
26.8 \\
\end{array}$ & $\begin{array}{l}10.5 \\
\text { No } \\
\text { No } \\
\text { No } \\
\text { No } \\
8.9 \\
12.1 \\
7.5 \\
11.6 \\
\text { No } \\
\end{array}$ & $\begin{array}{l}18.4(18.6) \\
13.7 \\
5.7 \\
16.4 \\
13.1 \\
6.35(7.5) \\
5.3(4.0) \\
5.6(6.4) \\
7.1(4.5) \\
16.1\end{array}$ \\
\hline $\begin{array}{l}\$ 2.5 \mathrm{SD} \\
\text { Normal }\end{array}$ & 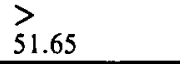 & $<$ & $\begin{array}{l}< \\
13.4\end{array}$ & $\begin{array}{l}<< \\
7.4(6.7)\end{array}$ \\
\hline
\end{tabular}

No $=$ not obtained. The values of TB (in brackets) were calculated from the corrected values of SEPC i.e. [SEPA - (SEPC - 0.8)].

* designates a markedly dispersed abnormal wave form.

recorded at Erb's point. This numerically small difference $0.8 \mathrm{~s}^{3}$ is significant $(\mathrm{p}<0.01)$.

The mean onset latency of the somatosensory response recorded over the contralateral cortex (SEPA) was $15.5 \pm 0.1 \mathrm{ss}^{-3}$. Thus the mean transit time from $\mathrm{C}_{7}$ to the contralateral cortex using the F-wave method (SEPA - TA) was $5.3 \pm 1.0 \mathrm{~s}^{-3}$ compared to $4.6 \pm$ $0.84 \mathrm{~s}^{3}$ when calculated from SEPC (SEPA - SEPC). The mean difference of $0.74 \pm 1.1 \mathrm{ss}^{-3}$ is again significant $(p<0.02)$ see Table 1 . The histogram (Fig. 1) compares in graphical form the transit time $\left(\mathrm{s}^{-3}\right)$ from wrist to $\mathrm{C}_{7}$, Erb's point to $C_{7}$, and $C_{7}$ to the contralateral sensory cortex, as computed from the F-wave response and SEPC. The transit time from $\mathrm{C}_{7}$ to the cortex (TB) is significantly slower using the $\mathrm{F}$-wave method as compared to TB calculated from SEPC $(p<0.02)$. Figure 2 is an example from a normal subject of the somatosensory evoked responses namely; cervical (SEPC) and cortical (SEPA), and also the mixed nerve ac-

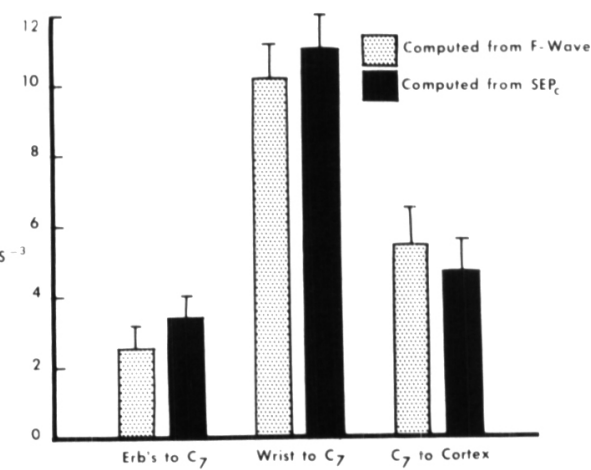

Figure 1 - Comparison of transit times from Erb's point to $C_{7}$, wrist to $C_{7}$, and $\mathrm{C}_{7}$ to cortex determined from the $\mathrm{F}$ wave response and cervical somatosensory response $\left(\mathrm{SEP}_{\mathrm{C}}\right)$.

tion potential recorded from Erb's point. The arrows indicate the onset latency of each response.

The rationale for recording the response over Erb's point was to aid in deciding the onset latency of SEPC. The two recording sites are so close (about $14 \mathrm{~cm}$.) that the possibility of a volume conducted response from Erb's point contaminating SEPC had to be considered. In the example shown, the mixed nerve action potential is virtually over before the onset of SEPC. The cervical somatosensory response is, however, not always so clearly delineated as in the example. Matthews et al. (1974) have shown that the main negative (upgoing) wave is often "indented" by one and sometimes two small positive waves. We believe that the first of these small positive waves (present in about one third of normal subjects) is volume conducted from Erb's point. Although there is presently no proof for this argument in man, we have temporarily decided it is more correct to take the onset of SEPC from the second small positive dip, if present. The same concern of some volume conducted contamination of SEPA by SEPC has to be considered in measuring the onset latency of SEPA. It will be seen (Fig. 2) that the cortical response begins (usually as a small positivity) after the cervical response has been completed (Cracco and Cracco, 1976). To achieve a more accurate measurement of the onset latencies, a fast sweep speed $\left(5 \mathrm{~s}^{-3}\right)$ with a $5 \mathrm{~s}^{-3}$ preanalysis delay was utilized in the normal subjects. Clearly, a large part of the cortically evoked response will not be visualized as is shown in Fig. 2. This is of same relevance when considering the abnormal state (see below).

A good linear relationship $(r=0.84)$ was found between the onset latency of SEPC and arm length (Fig. 3). A similar relationship was found between $\mathrm{TA}$ and arm length, but the correlation coefficient dropped to 0.71 .

Table 2 summarizes the electrophysiological data from 10 patients with suspected "spinal" multiple sclerosis (see discussion). Their clinical details are briefly outlined in the appendix.

In 5 patients, no convincing cervical somatosensory response was obtained. This is considered abnormal, since SEPC can invariably be obtained in normal subjects. In the remaining 5 patients, the response was of normal latency. The onset latency of SEPA was prolonged significantly in 5 patients. In four others (cases 3,6,7 and 9 ), the response, although of normal latency, was markedly dispersed in shape (see Fig. 4). No attempt has been made to measure the duration of SEPA 


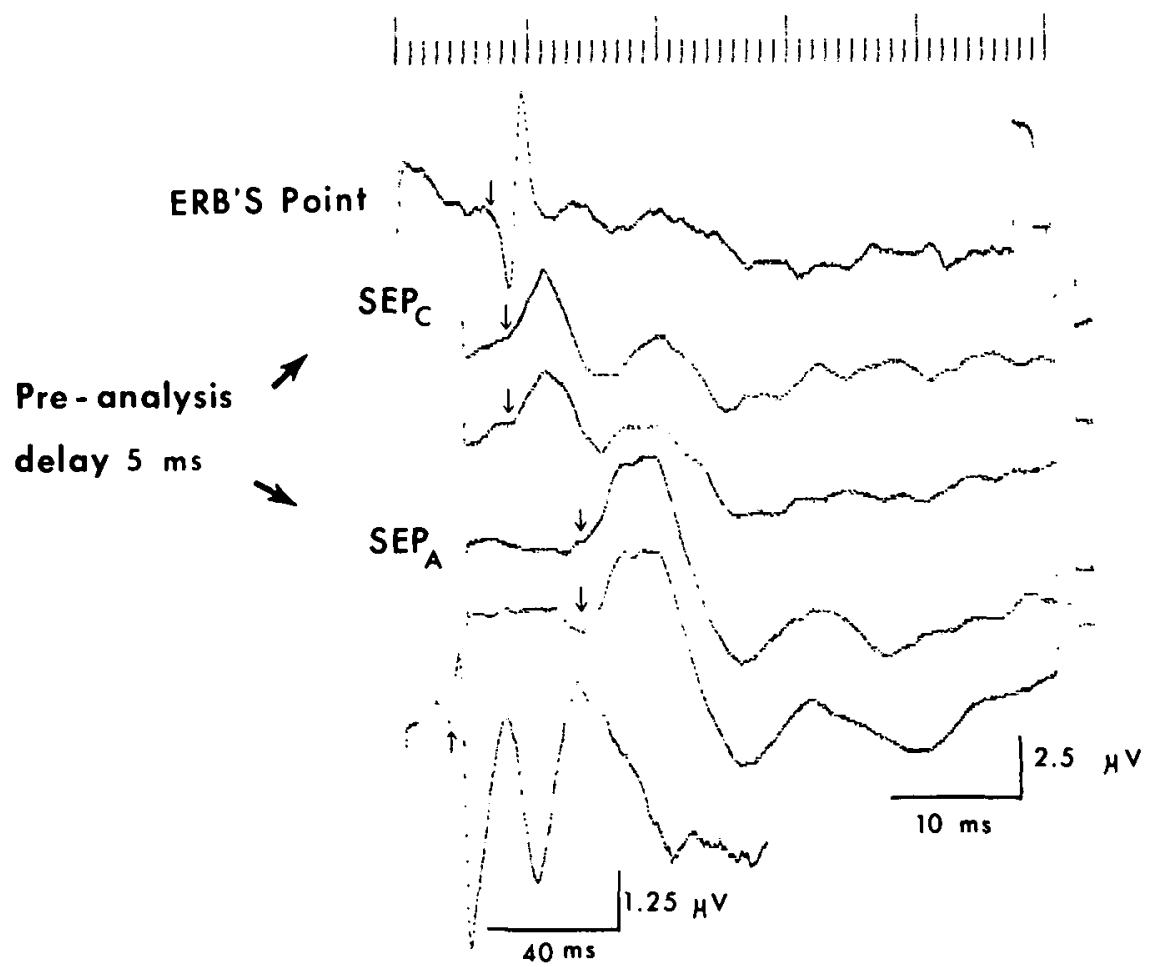

Figure 2-Example of normal mixed nerve action potential recorded at Erb's point (top), cervical somatosensory response (SEPC) - middle, and cortical somatosensory response (SEPA) - third trace. This is also shown at a slower sweep speed and higher magnification - bottom trace. Two separate trials of SEPC and SEPA are shown. A pre-analysis delay of $5 \mathrm{~s}^{-3}$ was used in evoking these.

systematically in normal subjects, but this would be a valuable characteristic. TB calculated by (SEPA - TA) was abnormally prolonged in 5 patients in

whom SEPC was obtainable. Of the 5 patients in whom SEPC could be recorded, two (cases 1 and 6) also had prolongation of $\mathrm{TB}$ as measured by

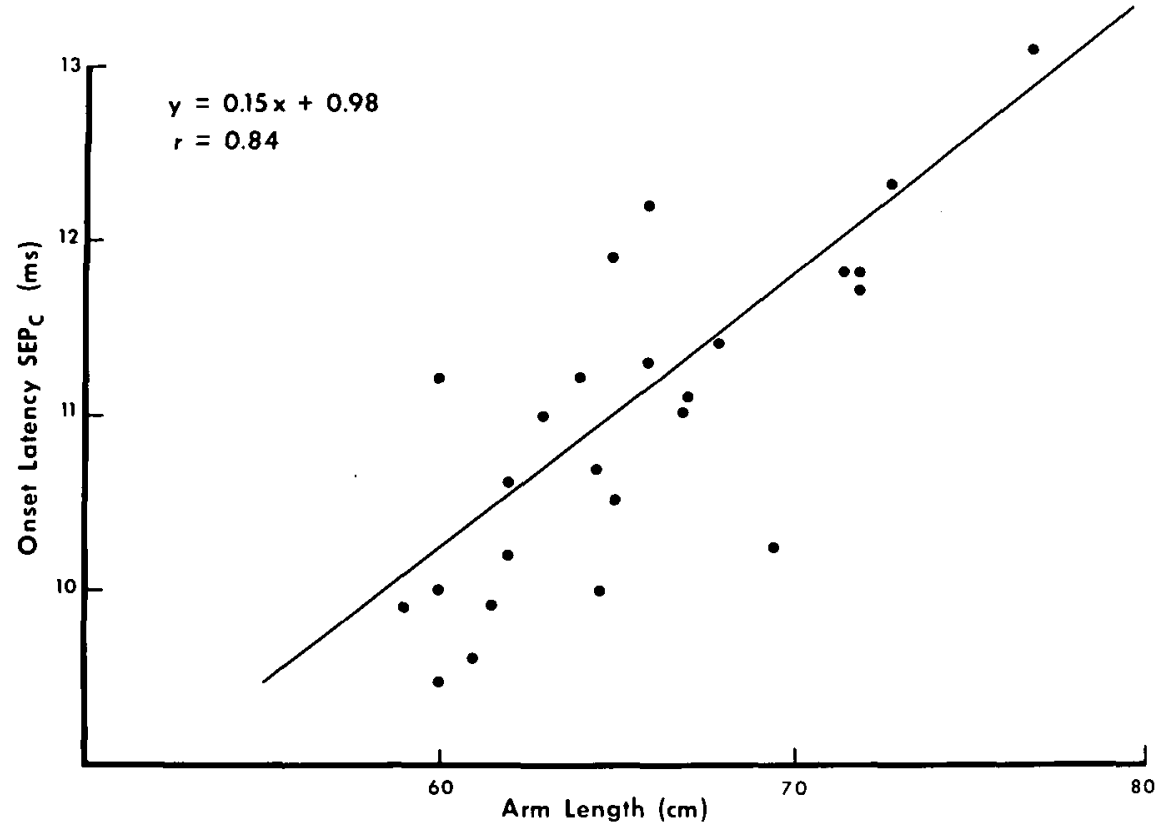

Figure 3-The regression line relates arm length to onset latency of cervical somatosensory response (SEPC). A similar linear relationship holds true for arm length and TA, calculated from the F-wave response in the same control population and is given by $y=$ $0.1 x+4.02(r=0.71)$.

(SEPA - SEPC). Thus 6 out of the 10 patients studied showed evidence for a lesion between $\mathrm{C}_{7}$ and the cortex, i.e. prolongation of TB.

\section{DISCUSSION}

In this study, the transit time from the wrist to the $C_{7}$ spinous process has been determined by two different methods. Using the $\mathrm{F}$-wave response, the mean transit time of $10.1 \mathrm{~s}^{-3} \mathrm{com}-$ pared favorably with our previous mean value of $10.4 \mathrm{~s}^{-3}$ (Eisen et al., 1977a). This would indicate that despite the variability of the F-wave response when recorded from a given muscle in a given individual (Upton et al., 1971), the technique in any one laboratory can give reproducible results. The onset latency of the cervical somatosensory response, a measure of the transit time over the same segment of nerve, was significantly slower. The mean value obtained (10.9 s- ${ }^{3}$ ) can be compared to the average of $10.6 \mathrm{~s}^{-3}$ reported by Matthews et al. (1974), who made the first systematic study of the cervical somatosensory response. Our mean onset latency of $15.5 \mathrm{~s}^{3}$ for the cortically evoked somatosensory response obtained with median nerve stimulation at the wrist (SEPA) is also in keeping with that originally described by Dawson (1956) and Goff et al. (1962), as well as that recently described by Dorfman (1977).

There is now ample evidence that the F-wave is mediated entirely through motor fibers (Magladery and McDougal, 1950; Gassel and Weisendanger, 1965; Thorne, 1965; McLeod and Wray, 1966; Mayer and Feldman, 1967; Miglietta, 1973). Conversely, the cervical somatosensory response is mediated, for the most part if not entirely, via sensory fibers (Matthews et al., 1974). Conduction mediated through sensory fibers in man is known to be faster than motor fibers (Dawson, 1956), but the magnitude of the difference is disputable (Magladery et al., 1951; Eisen et al., 1977b). Therefore, it was surprising that the transit time from the wrist to $C_{7}$ obtained by measuring the onset latency of SEPC ("sensory fibers") was slower rather than faster than that determined by using the F-wave method ("motor fibers"). 


\section{Case}

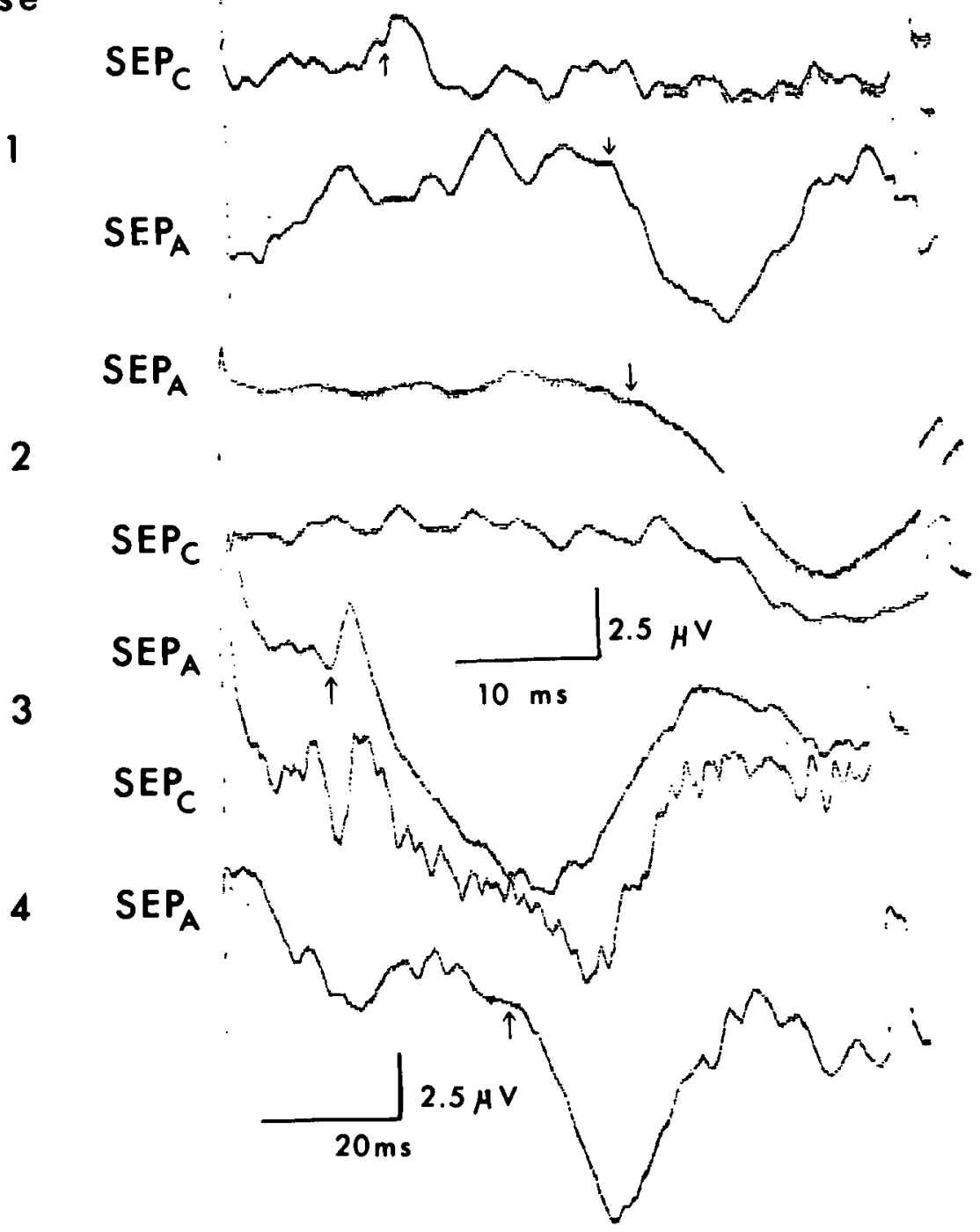

Figure 4-Examples of traces from the first 4 cases of patients with suspected multiple sclerosis (see table 2). SEPC was obtained from case 1 only and is of normal latency (arrow). SEPA in case 1,2, and 4, are of prolonged latency and dispersed shape (compare to fig. 2). The apparent negative wave seen in SEPA of case 1 was not time locked. In case 3, SEPA is of normal latency, but again the wave form is very dispersed. The upper 4 traces are at twice the sweep speed of the lower three traces.

The mean difference between the two transit times of $0.77 \mathrm{~s}^{3}$ (Table 1) may be explained by a single synaptic delay of approximately one millisecond. Possible sites for this delay of the latency of SEPC could be the dorsal column nuclei, spinal interneurones, or even the dorsal root ganglia.

If one takes into account this delay at or near the dorsal root gaglion, it becomes necessary to subtract $0.8 \mathrm{mil}$ lisecond (Table 1) from SEPC to include the central delay. If this is done, the mean transit time from the wrist to $C$, would be the same whether using the F-wave or cervical somatosensory response, which become interchangeable. Similarly, TB becomes equivalent whichever method is used. Validating the equality of both methods by the necessary corrective factor is not merely of academical interest. The $\mathrm{F}$-wave response is technically easier to obtain. Indeed, in confirmed multiple sclerosis as well as other diseases associated with cortico-spinal tract involvement this response is, in our experience, often of higher amplitude than normal. Presumably, this reflects release of anterior horn cell inhibition from higher centers. In contrast, the cervical somatosensory response may be abnormal in almost 90 percent of patients with confirmed multiple sclerosis (Small et al., 1977). Abnormalities of SEPC were also found in 40 percent of patients with purely ocular manifestations of multiple sclerosis by Small et al., (1977). However, it is not stated whether this represented a delay in latency or an absent response, which occurred in 4 of our 6 patients. As such, TB could still be calculated using the F-wave method.

Approximately 10 to 15 percent of patients with presumed multiple sclerosis run a lengthy and relatively benign course, which is usually progressive. In these patients, the clinical neurological deficit appears to be limited to evidence for a myelopathy. This "progressive spinal syndrome" (McAlpine and Compston, 1952; Leibowitz et al., 1967; Cärde and Kjellin, 1971; Leibowitz and Alter, 1973; Link et al., (1976) may initially be manifested by little more than hyperreflexia in the lower limbs. With time, sustained ankle clonus, extensor plantar responses, absent abdominal reflexes, and an objective sensory deficit usually develop as isolated phenomena or in combination. Although the appearance of these signs satisfies the physician as to the existence of true pathology, absence of signs above the neck still makes the diagnosis of multiple sclerosis suspect. Objective evidence for disease above the level of the lower cervical spinal cord, as indicated by slowing of conduction time from $\mathrm{C}_{7}$ to the contralateral cortex (TB), would support the clinical suspicion of multiple sclerosis.

Sixty percent of our admittedly small group of patients, with clinical features indicating only "spinal pathology" (see appendix), demonstrated a slowing of $\mathrm{TB}$, thus confirming the presence of a lesion at more than one anatomical site. Clearly, this type of physiological investigation must be extended to a larger group of similar patients before its real value can be substantiated. Bynke et al., (1977) have recently shown an abnormality of the visual evoked response in 76 percent of 25 patients with the "progressive spinal form" of multiple sclerosis. A combination of this technique and measurement of TB might give an even higher diagnostic yield than either technique alone. 
The type of approach employed in the present study should also complement other physiological techniques that are providing valuable support in the diagnosis of multiple sclerosis. These have recently been reviewed by McDonald and Halliday (1977). In addition, this technique should prove useful in following the natural history of multiple sclerosis and its response to future therapy.

The present study has shown that the transit time from wrist to $\mathrm{C}_{7}$ derived from the $\mathrm{F}$-wave response can be equated with the transit time over the same segment of nerve using the cervical somatosensory response, providing a corrective factor of 0.8 is applied to the latter. Thus the transit time from the wrist to $\mathrm{C}_{7}\left(\mathrm{~s}^{-}{ }^{3}\right)=$ $($ SEPC -0.8$)=$ TA, which is the transit time over the same segment employing the $\mathrm{F}$-wave response.

\section{APPENDIX}

Case 1 (J. H. female 40) Four year prior to testing, weakness and numbness of both legs. Since then, fleeting parathesiae of both hands and recurrent weakness of legs, more marked on the right.

Examination at time of testing: Hyperreflexia in the lower limbs, unsustained ankle clonus on the right. Reflexes in the upper limbs brisk. Toes downgoing, abdominal reflexes present. Sensory examination normal, but subjective tingling right hand. Cranial nerves normal. IGG 15 $\mathrm{mg} \%$, myelogram normal.

Case 2 (J.L. female 42) Ten years slowly progressive weakness and spasticity of legs, more marked on right.

Examination at time of testing: Marked spasticity of both legs, with hyper-reflexia and bilateral ankle clonus. Bilateral extensor plantar responses and absent abdominal reflexes. Reduced vibration in the feet. Normal bladder function and no abnormalities of the cranial nerves. Brisk finger flexion. IGG $8 \mathrm{mg} \%$, myelogram normal.

Case 3 (F.A. female 46) Slowly progressive weakness of both legs for 6 years prior to testing, associated with "ascending" numbness to level of the mid-trunk. Urinary urgency and stress incontinence.

Examination at time of testing: Moderate spasticity of the legs, marked hyper-reflexia. Bilateral extensor plantars and absent abdominal reflexes. Brisk finger flexion bilaterally. Diminution to pinprick with a fading level at $T_{4}$. Vibration markedly diminished in the legs but normal position sense. Normal sphincter function, and no abnormality of cranial nerves. IGG 33 $\mathrm{mg} \%$, myelogram normal.

Case 4 (E.A. female 47) Two years prior to testing, "giving way" of left leg, and urinary incontinence.

Examination at time of testing: Mild spasticity of both legs, more so on the left. Hyper-reflexia with unsustained ankle clonus on the left. Bilateral extensor plantar responses, and absent abdominal reflexes. Brisk finger flexion. No abnormality of the cranial nerves. IGG $10 \mathrm{mg} \%$, myelogram normal.

Case 5 (T.S. male 29) One year prior to testing, an episode of numbness left leg which recurred 4 months ago. Occasional "stiffness" of both legs.

Examination at time of testing: Hyperreflexia in the lower limbs. Toes downgoing, and abdominal reflexes present. No abnormality of the cranial nerves. IGG 5 $\mathrm{mg} \%$ (myelogram not done).

Case 6 (A.L. female 23) One week prior to testing, an acute episode of ascending numbess beginning in the legs which within 48 hours reached and remained at a segmental level of $\mathrm{T}_{4}$.

Examination at time of testing: Mild weakness of the legs, with hyper-reflexia and bilateral extensor plantar responses. Abdominal reflexes present. Diminished pinprick to a fading level at about $T_{4}$. No sphincter disturbance and no abnormality of cranial nerves. IGG $15 \mathrm{mg} \%$, myelogram normal.

Case 7 (M.S. male 38) Numbness of legs intermittently for 6 years. Two years progressive difficulty walking and recently clumsy left hand.

Examination at time of testing: Spasticity of both legs with marked hyperreflexia and left extensor plantar response. Brisk finger flexion bilaterally. Diminished vibration and position sense both feet and left hand. No abnormality of cranial nerves. IGG $11 \mathrm{mg} \%$, myelogram normal.

Case 8 (F.B. female 32) Numbness of left hand and both thighs intermittently since age 19. Legs fatigue with exercise, a more permanent complaint in the last year.

Examination at time of testing: Very brisk reflexes in the legs with spread. Plantar responses equivocal. Brisk reflexes in the upper limbs. Normal sensory exam and no abnormalities of the cranial nerves. IGG $5 \mathrm{mg} \%$, (myelogram not done).

Case 9 (M.S. female 42) Two and a half weeks prior to testing, woke up with numbness of both hands, and a tight band like sensation around the mid trunk. Numbness also felt down both legs. Unsteady when walking and has dropped things from both hands.
Examination at time of testing: Symptoms have remained the same. Reflexes in the upper limbs brisk, and very brisk in the lower limbs. Plantar responses equivocal bilaterally. Sensory exam did not reveal an objective level, and proprioception and vibration sensation were normal. IGG 11 $\mathrm{mg} \%$, myelogram normal.

Case 10 (B.C. female 36) Two years steadily progressive difficulty walking - legs feel stiff. Urinary frequency and urgency. 6 weeks intermittent numbness of both hands. No visual complaints or dysarthria.

Examination at time of testing: Evidence for a spastic paraparesis, with marked hyper-reflexia, bilateral ankle clonus, and a right extensor plantar response. Loss of vibration in the feet and poor position sense right foot. Reflexes in the upper limbs also very brisk, abdominal reflexes absent. No abnormalities of the cranial nerves. IGG 7 $\mathrm{mg} \%$ (done 6 months prior to test), myelogram normal.

\section{REFERENCES}

BYNKE, H., OLSSON, J. E. and ROSEN, I. (1977). Diagnostic value of visual evoked response, clinical eye examination and CSF analysis in chronic myelopathy. Acta Neurologica Scandinavica 56, 55-69.

CRACCO, R. Q. and CRACCO, J. B. (1976). Somatosensory evoked potential in man: Far field potentials. Electroencephalography and Clinical Neurophysiology $41,460-466$.

DAWSON, G. D. (1956). The relative excitability and conduction velocity of sensory and motor fibers in man. Journal of Physiology (Lond.) 131, 436-451.

DORFMAN, L. J. (1977). Indirect estimation of spinal cord conduction velocity in man. Electroencephalography and Clinical Neurophysiology, 42, 26-34.

EISEN, A. and NUDLEMAN, K. (In press) Cord to cortex conduction in multiple sclerosis. Neurology (Minneapolis).

EISEN, A., SCHOMER, D. and MELMED, C (1977a). The application of $F$ wave measurements in the differentiation of proximal and distal upper limb entrapments. Neurology (Minneapolis) 27, 662-668.

EISEN, A., SCHOMER, D. and MELMED, C. (1977b). An electrophysiological method for examining lumbosacral root compression. The Canadian Journal of Neurological Sciences, 4, 117-123.

GÄRDE, A. and KJELLIN, K. G. (1971) Diagnostic significance of cerebrospinal fluid examinations in myelopathy. Acta Neurologica Scandinavica, 47, 555-568.

GASSEL, $M$. $M$. and WIESENDANGER, $M$. (1965). Recurrent and reflex discharges in plantar muscles of the cat. Acta Physiologica Scandinavica, 65, 138-142.

GOFF, W. R., ROSNER, B.S. and ALLISON, T. (1962). Distribution of cerebral 
somatosensory evoked responses in normal man. Electroencephalography and Clinical Neurophysiology, 14, 697-713.

KIMURA, J. (1974). F wave velocity in the central segment of the median and ulnar nerves. A study in normals and in CharcotMarie-Tooth disease. Neurology (Minneapolis) 24, 539-546.

LEIBOWITZ, U. and ALTER, M. (1973) Multiple sclerosis: Clues to its cause. NorthHolland Publishing Co., (Amsterdam). pp. 83-117.

LEIBOWITZ, U. and HALPERN, L. and ALTER, M. (1967). Clinical studies of multiple sclerosis in Israel. V. Progressive spinal syndromes and multiple sclerosis. Neurology (Minneapolis) 17,988-992.

LINK, H., NORRBY, E. and OLSSON, J.E. (1976) Immunoglobulin abnormalities and measles antibody responses in chronic myelopathy. Archives of Neurology (Chicago) 33, 26-32.

MAGLADERY, J. W. and McDOUGAL, D. B. (1950). Electrophysiology of nerve and reflex activity in normal man. I. Identifica. tion of certain reflexes in the electromyogram and the conduction velocity of peripheral nerve fibers. Bulletin of the Johns Hopkins Hospital, 86, 265-290.
MAGLADERY, J. W., PORTER, W. E., PARK, A. M. and TEASDALL, R. D. (1951). Electrophysiological studies of nerve and reflex activity in normal man. IV. The two-neurone reflex and identification of certain action potentials from spinal roots and cord. Bulletin of the Johns Hopkins Hospital, 88, 499-519.

MATTHEWS, W. B., BEAUCHAMP, $M$. and SMALL, D. G. (1974). Cervical somatosensory evoked responses in man. Nature, 252 , 230-232.

MAYER, R. F. and FELDMAN, R. G. (1967). Observations on the nature of the $F$ wave in man. Neurology (Minneapolis) 17, 147-156.

McALPINE, D. and COMPSTON, N. (1952). Some aspects of the natural history of disseminated sclerosis. Quarterly Journal of Medicine. 21, 135-167.

MCDONALD, W. I. and HALLIDAY, A. M. (1977). Diagnosis and classification of multiple sclerosis. British Medical Bulletin, 33, 48.

McLEOD, J. G. and WRAY, S. H. (1966). An experimental study of the $F$ wave in the baboon. Journal of Neurology, Neurosurgery and Psychiatry, 29, 196-200.
MIGLIETTA, O. E. (1973). The F response after transverse myelotomy. In: New Developments in Electromyography and Clinical Neurophysiology, vol. 3, pp. 323327, edited by J. E. Desmedt. Karger: Basel.

RENSHAW, B. (1941). Influence of discharge of motor neurons upon excitation of neighbouring motor neurons. Journal of Neurophysiology, 4, 167-183.

SMALL, D. G., BEAUCHAMP, M. and MATTHEWS, W. B. (1977). Spinal evoked potentials in multiple sclerosis. Electroencephalography and Clinical Neurophysiology, 42, 141 (abstract).

THORNE, J. (1965). Central responses to electrical activation of the peripheral nerves supplying the intrinsic hand muscle. Journal of Neurology, Neurosurgery and Psychiatry, 28, 482-495.

TSUMOTO, T., HIROSE, N., NONAKA, S. and TAKAHASHI, M. (1972). Analysis of somatosensory evoked potentials to lateral popliteal nerve stimulation in man. Electroencephalography and Clinical Neurophysiology, 33, 379-388.

UPTON, A. R. M., McCOMAS, A. J. and SICA, R. E. P. (1971). Potentiation of "late" responses evoked in muscles during effort. Journal of Neurology, Neurosurgery and Psychiatry, 34, 699-711. 